\title{
UMA REFLEXÃO ACERCA DO PARADIGMA DE NOMES DEVERBAIS COM OS SUFIXOS - ÇÃO E -MENTO EM PORTUGUÊS BRASILEIRO CONTEMPORÂNEO
}

\author{
Natália Cristine PRADO ${ }^{1}$ \\ Gisela Sequini FAVARO ${ }^{2}$
}

http://dx.doi.org/10.21165/gel.v18i2.3112

Resumo: O objetivo deste artigo é fazer uma reflexão acerca do paradigma dos nomes deverbais com os sufixos -ção e-mento em Português Brasileiro Contemporâneo, doravante PBC, a partir de estudos realizados por Basílio (1987) e Rio-Torto (1998). Para observarmos os fenômenos de produtividade, lexicalização e bloqueios envolvendo o paradigma da formação de nomes em -ção e -mento no PBC, foi selecionado um grupo de palavras derivadas com os sufixos enfocados a partir de uma mesma base do total de palavras com esses sufixos que foram encontradas no Dicionário Eletrônico Houaiss da Língua Portuguesa. Posteriormente, deste grupo analisamos as duplas de palavras de mesma base formadas com os sufixos selecionados, e assim procuramos no banco de dados do LabLEX (Laboratório de Estudos Lexicográficos da UNESP) todos os contextos em que ocorrem palavras terminadas por -ção e -mento. Nesta oportunidade, apresentaremos um total de 19 pares de palavras derivadas em -ção e -mento com dois exemplos de contextos em que cada uma delas ocorre. A partir dessa amostra dos nomes e de seu uso, pretendemos observar as principais diferenças que ocorrem quando temos duas palavras derivadas em -ção e -mento a partir de uma mesma base no PCB.

Palavras-chave: Nomes deverbais. Português Contemporâneo. Paradigma.

\footnotetext{
1 Universidade Federal de Rondônia (UNIR), Porto Velho, Rondônia, Brasil; natalia_cristine_prado@yahoo.com.br; https://orcid.org/0000-0001-8947-4330

2 Universidade de São Paulo (USP), São Paulo, Brasil; giselasfavaro@gmail.com; https://orcid.org/0000-0002-7321-7935
} 
- Uma reflexão acerca do paradigma de nomes deverbais com os sufixos -ção e -mento em Português Brasileiro Contemporâneo

\title{
A REFLECTION ON THE PARADIGM OF DEVERBAL NAMES WITH THE SUFFIXES -ÇÃO AND -MENTO IN CONTEMPORARY BRAZILIAN PORTUGUESE
}

\begin{abstract}
This article aims to reflect on the paradigm of the deverbal names with the suffixes -ção and -mento in Contemporary Brazilian Portuguese (PBC), from studies carried out by Basílio (1987) and Rio-Torto (1998). To observe the phenomena of productivity, lexicalization, and blockages involving the paradigm of the formation of names in -ção and -mento in PBC, a group of derived words with the suffixes focused on the same base of the total of words with these suffixes were selected, that were found in the Houaiss Electronic Dictionary of the Portuguese Language. Subsequently, from this group, we analyzed the pairs of words of the same base formed with the selected suffixes, and thus we searched the LabLEX (Laboratory of Lexicographic Studies at UNESP) database for all contexts in which words ending with -ção and -mento occur. In this opportunity, we will present a total of 19 pairs of words derived in -ção and -mento with two examples of contexts in which each one occurs. From this sample of names and their use, we intend to observe the main differences that occur when we have two words derived in -ção and -mento from the same base in the PCB.
\end{abstract}

Keywords: Deverbal names. Contemporary Portuguese. Paradigm.

\section{Introdução}

Segundo Rio-Torto (1998), o sistema de formação de palavras duma língua assenta num conjunto de procedimentos de natureza morfo-léxico-semântico-sintática que, a partir de determinado número de elementos de base, constrói outros destes decorrentes. Num mesmo paradigma, podemos ter mais de um processo de formação de palavras, como podemos ver no paradigma que dá origem a nomes deverbais com conteúdo semântico de ação (que a autora denomina RFP ACT - "nomina actionis"), parafraseáveis por Rio-Torto (1998, p. 26) "o fato de V" ou "acção, processo, estado (decorrente) de V".

A autora ainda observa que vários sufixos agem na constituição deste paradigma, como o sufixo -agem (contagem), -ção (elaboração) e -mento (acolhimento). Partindo dessas observações da autora acerca do Português Europeu, vamos explorar mais detalhadamente a formação de palavras com dois sufixos que atuam nesse paradigma: os sufixos -ção e -mento no Português Brasileiro Contemporâneo (PBC).

Assim, observamos pelo uso que, quando queremos nos referir ao fato de que vamos receber alguém, usamos recepção, palavra que carrega o sentido de receber 
como "ter convidados". Já recebimento é usado com o sentido geral de receber objetos, dinheiro, entre outras coisas. Qualquer falante nativo percebe este tipo de diferença que é algo que um aprendiz de Português como língua estrangeira vai percebendo conforme vai interagindo no idioma.

Se uma pessoa falar, por exemplo, que não pode sair de sua casa porque tem que fazer a "recepção de uma encomenda" ou porque estará oferecendo "um recebimento para os amigos" iria soar estranho ou talvez irônico dependendo do sentido que o falante quer dar ao que foi dito; este é o tipo de engano que um estudante de Português como segunda língua pode cometer até dominar melhor o uso do idioma.

Como observa Basílio (1987), este é um exemplo de diferença de uso já que a carga semântica de "pessoa" ou de "coisa" não pode ser atribuída ao sufixo nominalizador. Como podemos observar, a palavra recepção adquiriu também significado de reunião festiva, festa ou coquetel (seguindo no verbete recepção do Dicionário Houaiss). Sendo assim, podemos dizer que essa palavra passou por um processo que Sandmann (1991) chama de lexicalização, pois seu significado não é apenas a soma da base com o sufixo.

Esse fenômeno traz algumas consequências para o uso das palavras derivadas em -ção e -mento já que, de acordo com o autor, "a lexicalização tem também suas consequências, no sentido de estimular ou motivar a produção de novas unidades, neutralizando restrições ou limitações às regras ou afastando os bloqueios que se lhes impõem" (SANDMANN, 1991, p. 30).

Nossa intenção neste artigo é refletir sobre as diferenças que podem existir na formação e/ou uso de nomes com o sufixo -ção e -mento, já que, segundo Basílio (1987, p. 22), há uma multiplicidade de processos que podem afetar uma construção; ou na utilização e disseminação de situações naturais de metáfora e extensão de sentido; ou na presença insuspeitada de funções de certos formativos.

\section{O comportamento dos sufixos -ção e -mento no português}

De acordo com Silveira e Schwindt (2016), do ponto de vista histórico, os afixos -ção e -mento já concorriam, desde o latim, para a produção de substantivos abstratos derivados de verbos, tendo, inclusive, contextos de aplicações coincidentes. Segundo Quadros (2015), a vantagem do sufixo -ção sobre -mento, já presente no século XVII, não fez com que -mento perdesse sua produtividade. O resultado em termos sincrônicos é a expectativa por formações de substantivos tanto em -ção quanto em -mento, podendo, muitas vezes, como dissemos, concorrerem em contextos idênticos. 
- Uma reflexão acerca do paradigma de nomes deverbais com os sufixos -ção e -mento em Português Brasileiro Contemporâneo

Todavia, Silveira e Schwindt (2016), baseados no trabalho de Basílio (1996), atestam que bases derivadas favorecem a utilização de -ção, enquanto as primitivas favorecem a nominalização em -mento, aparentemente, -ção apresenta melhores condições de produção do que -mento, uma vez que parece existir uma tendência mais acentuada de formações a partir de bases derivadas.

Assim, a autora chama a atenção para o fato de que as formas nominalizadas adquirem muitas vezes significados diferentes em função de seu uso; como exemplo ela nos mostra o que acontece com os derivados do verbo receber: recepção e recebimento. Observando diacronicamente, vemos que a primeira é uma formação mais antiga.

Segundo Viaro (2003), recepção veio diretamente do latim receptĭo enquanto recebimento foi formada a partir do verbo receber seguindo as regras de formação de palavras da língua portuguesa, por isso dizemos que em recepção há uma base presa culta recep-. Olhando para essas palavras numa visão sincrônica, vemos que são palavras de mesma base, sendo que a palavra recepção sofre maiores mudanças de ordem morfofonológica que a palavra recebimento. Observando a formação dessas palavras de acordo com a regra [Xb + -ção/-mento], vemos que ocorrem mudanças fonológicas na base verbal:

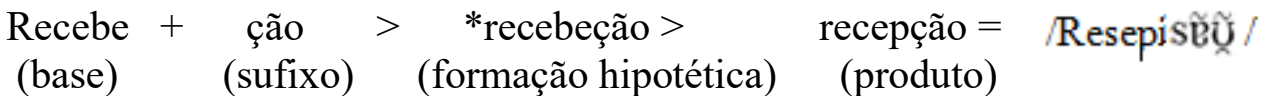

Numa interpretação sincrônica, não temos * recebeção, pois ocorre um processo de ensurdecimento: a consoante oclusiva bilabial sonora /b/ assimila o traço [-vozeado] da fricativa alveolar surda /s/ do sufixo -ção transformando-se na consoante /p/ oclusiva bilabial surda. Além disso, observamos também uma mudança na vogal temática /e/ que é média e passa para a vogal alta /i/, esta alomorfia também acontece em recebimento.

Apesar das diferenças na base dos nomes, são duas formas de um mesmo paradigma, ambos são nomes abstratos parafraseáveis por o "fato de receber" ou "ação decorrente de receber", seguindo Rio-Torto (1998), mas, como observa Basílio (1987), teoricamente poderíamos ter apenas uma forma nominalizada para o verbo receber ou qualquer uma das formas poderia apresentar qualquer um dos significados gerais possíveis com este verbo. No entanto, verificamos que certos significados são expressos com uma das formas, outros com a outra. 
Neste viés, podemos afirmar que as derivações deverbais em -ção e em -mento podem estar sujeitas a bloqueio morfossemântico, como propõem Aronoff (1976) e Basílio (1987). Assim, um vocábulo como *divulgamento em princípio não se faz produtivo na língua por já existir a palavra divulgação, que se assemelha à primeira em termos de significado e da regra de formação de palavras ${ }^{3}$ a que se submete.

O fenômeno da produtividade dos sufixos -ção e -mento também foi discutido através de análises realizadas pela teoria da Morfologia Distribuída. Segundo Oliveira (2016), a adjunção dos sufixos nominalizadores -ção e -mento às raízes verbais forma substantivos abstratos, como perseguição, obrigação, posicionamento, questionamento etc.; porém isto não ocorre de forma aleatória, pois temos, por exemplo, distribuição e não *distribuimento, assim como endividamento, e não *endividação. Sendo assim, explora-se a hipótese de que as raízes verbais impõem restrições de cunho aspectual às formações derivadas, que vão permitir ora a adjunção da base verbal ao sufixo nominalizador -ção, ora ao sufixo nominalizador-mento.

Para Oliveira (2016), o sufixo -ção é um morfema agentivo/causativo, já que se adjunge a verbos agentivos/causativos, que exigem um agente: nomear/nomeação, declarar/declaração, punir/punição, reparar/reparação, fundir/fundição etc. Baseada no estudo de Chafe (1979), a autora afirma que morfema causativo converte uma raiz verbal que é processo em uma que, por derivação, denota tanto processo como o resultado da ação. Por sua vez, as formas verbais que permitem a adjunção de -mento têm agentes implicados, conforme propõe Oliveira (2016), por situações com causação interna.

Segundo a autora, a noção [causação interna] é então decorrência semântica do molde morfossintático [raiz +-mento]. Desta forma, -mento é um morfema não-agentivo, dado que se adjunge a verbos não-agentivos e não-causativos: amadurecer, florescer, esfriar, falecer, envelhecer, embelezar, enfraquecer, fingir etc. As raízes verbais que compõem as derivações denotam mudança de estado e as formações derivadas exprimem o resultado da mudança de estado.

Neste viés, de acordo com os estudos feitos por Oliveira (2016), os verbos que se adjungem ao sufixo nominalizador -ção denotam um evento não causado internamente, o que implica em causa externa ou agente, e têm como resultado uma forma derivada que denota o resultado da ação ou da agentividade. Por sua vez, os verbos que se adjungem ao sufixo -mento denotam mudança de estado causada internamente, o que implica causa interna, e têm como resultado uma forma derivada que denota mudança de estado. Passemos agora para a descrição do corpus e dos dados coletados.

3 Sobre este tema, conferir o trabalho de Aronoff (1976). 
- Uma reflexão acerca do paradigma de nomes deverbais com os sufixos -ção e -mento em Português Brasileiro Contemporâneo

\section{Escolha do corpus}

Para observar os fenômenos de produtividade, lexicalização e bloqueios envolvendo o paradigma da formação de nomes em -ção e -mento no PBC, primeiramente selecionamos um grupo de palavras derivadas com os sufixos enfocados a partir de uma mesma base do total de palavras com esses sufixos que foram encontradas no Dicionário Eletrônico Houaiss da Língua Portuguesa versão 1.0.7 de setembro de 2004, que possui cerca de 228 mil verbetes.

Deste grupo selecionamos as duplas de palavras de mesma base formadas com os sufixos selecionados que foram encontradas em contextos de uso no PBC através de um recorte do banco de dados do Laboratório de Estudos Lexicográficos da UNESP (LabLEX). Este laboratório, criado com recursos da FAPESP e da UNESP, conta com diversos equipamentos e programas especiais de construção, gerenciamento e manipulação de um corpus que possui cerca de 11 milhões de ocorrências do português do Brasil colhidas em diversas fontes, desde as literárias até as jornalísticas, das quais podemos citar 7.100.000 ocorrências correspondentes a quatro anos de publicação da revista Veja (1992-95) e 59.400.000 correspondentes a dois anos de publicação da Folha de S. Paulo (1994-95).

Este corpus, com vários textos escritos no Brasil, reúne vozes de inúmeros autores e cobre uma rica variedade de temas, gêneros e enfoques, o que nos permitirá uma boa observação do uso das palavras selecionadas. Assim, procuramos no banco de dados do LabLEX todos os contextos em que ocorrem palavras terminadas por -ção e -mento nos documentos disponíveis a partir de 1950 até o ano 2000. Este estudo resultou em dois arquivos de imagem no formato TIFF que foram convertidos em dois documentos do Microsoft Word com 4.490 páginas (arquivo com 46,1 MB) para o sufixo -ção e 1841 páginas (arquivo com $18 \mathrm{MB}$ ) para o sufixo -mento.

Nesses documentos, usamos a ferramenta localizar disponível no próprio Word para encontrar os contextos em que as palavras ocorriam. Procuramos também no site www.google.com.br pela ocorrência dessas palavras num contexto de uso em sites brasileiros. Por fim, fechamos um corpus com um total de 19 pares de palavras derivadas em -ção e-mento com dois exemplos de contextos em que cada uma delas ocorre. A partir dessa pequena amostra dos nomes e de seu uso, pretendemos observar as principais diferenças que ocorrem quando temos duas palavras derivadas em -ção e -mento a partir de uma mesma base. 


\section{Sinonímia - breves reflexões}

Ao realizarmos nossas reflexões acerca do paradigma de nomes deverbais com os sufixos -ção e -mento em Português Brasileiro Contemporâneo, faz-se necessário apresentar algumas palavras sobre o conceito de sinonímia. Vale ressaltar que o intuito deste artigo não é adentrar em uma discussão mais minuciosa acerca deste assunto, uma vez que o propósito das análises aqui apresentadas é observar as principais diferenças que ocorrem quando temos duas palavras derivadas em -ção e -mento a partir de uma mesma base.

De modo geral, as palavras podem ser consideradas sinônimas quando apresentam a possibilidade de serem substituídas umas pelas outras, em um determinado contexto, sem acarretar alteração de sentido. Lyons (1979), ao abordar as relações de sinonímia, propõe que os valores afetivos inerentes a um lexema não se separam na linguagem cotidiana. Sua grande contribuição é evidenciar que a sinonímia é dependente do contexto.

Lopes e Pietroforte (2004) também realizaram estudos sobre a sinonímia. Para os autores, termos são chamados sinônimos quando apresentam a possibilidade de se substituírem um ao outro em determinado contexto. Por exemplo, novo é sinônimo de jovem porque, no contexto homem novo, o termo novo pode ser substituído por jovem. No entanto, os autores ressaltam que não existem sinônimos perfeitos, porque eles não são intercambiáveis em todos os contextos. Isto significa que, no discurso, o enunciador pode tornar sinônimas palavras ou expressões que em outro contexto não o são.

Para Ilari e Geraldi (2006, p. 47), as expressões sinônimas são expressões entre as quais os locutores escolhem: a escolha é, no caso, uma "procura da palavra exata" a mostrar que duas expressões não são igualmente adequadas aos fins visados; essa escolha traduz frequentemente a preocupação de evocar ou respeitar um determinado nível de fala, um determinado tipo de interação, ou mesmo um certo jargão profissional. Logo, pode se afirmar que a sinonímia está ligada, diretamente, às intenções dos falantes, não podendo ser feita, de forma alguma, dissociada de um contexto, pois tal relação de sentido envolve a situação de uso da língua, as pretensões de quem produz o enunciado naquele instante e os interlocutores envolvidos.

Assim, para a elaboração das discussões dos resultados deste artigo, ao adotarmos o uso da expressão "o termo $X$ pode ser trocado ou substituído pelo termo Y sem prejuízo de sentido no contexto em análise", estamos querendo averiguar principalmente o paradigma de palavras derivadas em -ção e -mento a partir de uma mesma base em um 
- Uma reflexão acerca do paradigma de nomes deverbais com os sufixos -ção e -mento em Português Brasileiro Contemporâneo

mesmo contexto, ficando implícita uma possível relação de sinonímia ou não entre os vocábulos selecionados.

\section{Discussão e análise dos dados}

Segundo Rio-Torto (1998), existem alguns tipos principais de processos de formação de palavras: as operações aditivas, as subtrativas e as modificativas. A formação das palavras com os sufixos -ção e -mento que estamos aqui observando se dá por um processo aditivo de afixação.

Rocha (2003) classifica os sufixos -ção e -mento como sendo sufixos concorrentes já que, embora sejam distintos do ponto de vista fonético, apresentam o mesmo sentido e/ou função e formam nomes abstratos a partir de verbos. O autor classifica ainda esses sufixos como categoriais, pois "mudam a categoria lexical do produto, com relação à base" (ROCHA, 2003, p. 114) e, através da descrição de Rio-Torto (1998, p. 26) que nos mostra que essas palavras adquirem o significado acessório de "o fato de V" ou "acção, processo, estado (decorrente) de V", podemos também classificar esses sufixos como significativos, seguindo a terminologia de Rocha. Assim temos nesses nomes estruturas do tipo, conforme mostra o exemplo abaixo:

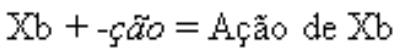

$$
\begin{aligned}
& \mathrm{Xb}+- \text { mento }=\mathrm{A} \text { ção de } \mathrm{Xb}
\end{aligned}
$$

Segundo Basílio (2006), as formações com -ção são as mais produtivas, correspondendo a quase $60 \%$ das formações regulares enquanto as formações em -mento correspondem a cerca de $20 \%$. A afirmação da autora pode ser confirmada pelos registros do dicionário Houaiss que, como dissemos, possui mais verbetes de palavras derivadas em -ção do que em -mento. Durante nossa observação dos verbetes do dicionário Houaiss, separamos aleatoriamente 50 pares de palavras derivadas com os sufixos estudados, porém quando fomos procurar por contextos em que ocorriam, percebemos que muitas, além de não estarem registradas no banco de dados do LabLEX, também só eram encontradas em sites portugueses; assim, como estamos restringindo nossa pesquisa às palavras derivadas em -ção e -mento que coexistem em uso no PBC, excluímos as palavras que ocorrem apenas na variedade europeia do português, chegando ao total de 19 pares de palavras observados. 
Um exemplo de palavras excluídas é o par branqueamento/branqueação. Branqueamento foi facilmente encontrada no banco de dados do LabLEX, já branqueação foi encontrada em sites portugueses principalmente em contextos de produção têxtil. No dicionário Houaiss encontramos o verbete branqueação descrito de maneira bastante sucinta, dizendo que se trata de um sinônimo de branqueamento (ato, processo ou efeito de branquear; branqueamento), já o verbete branqueamento é muito mais detalhado, com 10 acepções, incluindo seu uso na indústria têxtil e um regionalismo português em que branqueamento é usado para "lavagem de dinheiro".

Percebemos, assim, que enquanto no Brasil a forma preferida e a que aparece em contextos referentes à indústria têxtil é branqueamento, em Portugal é branqueação e a outra forma adquiriu lá uma especialização de sentido. Como vamos nos ater aqui apenas às comparações entre palavras de mesma base com os sufixos selecionados no PBC, não nos debruçaremos de maneira mais detalhada em casos de diferenças semânticas desses nomes no Português Europeu.

Uma das explicações para a dupla -ção e -mento ser preferida para a formação de nomes deverbais é, segundo Basílio, o fato de que ambos são semanticamente vazios em oposição aos demais. No entanto essa explicação vem caindo, pois, observações de formações neológicas em -ção, isto é, formas ainda não registradas em dicionários, mostram que este sufixo está adquirindo um traço semântico mais jocoso, brincalhão: o chamado -ção iterativo apontado por Maroneze (2005).

Sandmann (1991) aponta que o sufixo -ção é preferido por verbos terminados em -izar e -(i)ficar enquanto -mento ocorre preferencialmente com verbos em -ecer. A princípio isso parece ser uma motivação fonológica, mas a existência de formações como balizamento e deslizamento derivadas respectivamente de balizar e deslizar, em que, para o autor, não temos um verbo-base terminado em -izar, refutam esta hipótese mostrando que a motivação é de ordem morfológica. O autor lembra ainda que verbos formados por derivação parassintética preferem o sufixo -mento.

Para o autor, "constitui desafio mais complexo, em geral, determinar o porquê do estabelecimento da preferência entre determinada base e um sufixo, ou o como se estabeleceu essa 'afinidade', como o caminho foi se alargando e tornando mais 'fácil'" (SANDMANN, 1991, p. 42). Passemos agora para as análises dos dados. 
- Uma reflexão acerca do paradigma de nomes deverbais com os sufixos -ção e -mento em Português Brasileiro Contemporâneo

\section{Análise Semântica dos pares}

Olhando para as palavras nos contextos de uso encontrados, nota-se que, além de existirem mais formações em -ção, é provável que elas sejam mais usadas pelos falantes, já que ocorrem num número maior de contextos que a sua correspondente em -mento. Isso acontece porque ambas as formas são desbloqueadas (na terminologia de Sandmann, 1971) morfologicamente, ou seja, elas já foram criadas por isso a existência de uma das palavras não vai impedir a criação da outra, neste caso outros fenômenos passam a agir para diferenciá-las, como os processos de deriva semântica, descrito da seguinte forma pelo autor:

[...] fenômeno comum nas unidades lexicais que passam a integrar o rol das palavras usuais de uma língua, age no sentido de levantar as restrições ou de provocar o desbloqueio, entraves que limitam ou frustram a produtividade das regras de formação de palavras. (SANDMANN, 1991, p. 32).

O quadro abaixo traz o levantamento dos pares analisados e seus respectivos sentidos:

Quadro 1. Pares de palavras e seus sentidos (semântica)

\begin{tabular}{|c|c|c|c|}
\hline Base $+-c ̧ \tilde{a} o$ & Significado & Base +- mento & Significado \\
\hline abreviação & $\begin{array}{l}\text { termo técnico da } \\
\text { gramática; uma redução de } \\
\text { uma palavra. }\end{array}$ & abreviamento & encurtamento de tempo. \\
\hline aceleração & $\begin{array}{l}\text { ato ou efeito de acelerar(-se), } \\
\text { isto é, aumento progressivo } \\
\text { de velocidade. }\end{array}$ & aceleramento & $\begin{array}{l}\text { ato ou efeito de acelerar (-se), } \\
\text { isto é, aumento progressivo } \\
\text { de velocidade. }\end{array}$ \\
\hline acomodação & $\begin{array}{l}\text { local ou quarto para } \\
\text { hospedar alguém. }\end{array}$ & acomodamento & $\begin{array}{l}\text { local ou quarto para } \\
\text { hospedar alguém, } \\
\text { capacidade de adequação. }\end{array}$ \\
\hline bifurcação & $\begin{array}{l}\text { divisão ou separação de } \\
\text { alguma coisa em dois } \\
\text { ramos ou braços (tal como } \\
\text { uma forquilha). }\end{array}$ & bifurcamento & $\begin{array}{l}\text { divisão ou separação de } \\
\text { alguma coisa em dois ramos } \\
\text { ou braços (tal como uma } \\
\text { forquilha). }\end{array}$ \\
\hline brotação & $\begin{array}{l}\text { broto - planta jovem } \\
\text { ou tipo de reprodução } \\
\text { assexuada. }\end{array}$ & brotamento & $\begin{array}{l}\text { tipo de reprodução } \\
\text { assexuada. }\end{array}$ \\
\hline castração & $\begin{array}{l}\text { ato/ação de privar dos } \\
\text { órgãos da reprodução ou } \\
\text { algum tipo de limitação } \\
\text { sexual. }\end{array}$ & castramento & $\begin{array}{l}\text { ato/ação de privar dos } \\
\text { órgãos da reprodução. }\end{array}$ \\
\hline
\end{tabular}




\begin{tabular}{|c|c|c|c|}
\hline congelação & $\begin{array}{l}\text { ato ou efeito de congelar } \\
\text { (-se). }\end{array}$ & congelamento & $\begin{array}{l}\text { ato ou efeito de a autoridade } \\
\text { competente fixar valores, } \\
\text { preços, salários (sentido } \\
\text { metafórico). }\end{array}$ \\
\hline degradação & ato/ação de deteriorar. & degradamento & ato/ação de deteriorar. \\
\hline filtração & $\begin{array}{l}\text { ato/ação de filtrar de } \\
\text { modo a retirar impurezas. }\end{array}$ & filtramento & $\begin{array}{l}\text { de ato/ação de filtrar de } \\
\text { modo a retirar impurezas. }\end{array}$ \\
\hline isolação & ato/ação isolar. & isolamento & $\begin{array}{l}\text { ação/ato de separar algo } \\
\text { em determinado contexto, } \\
\text { estado da pessoa que vive } \\
\text { isolada. }\end{array}$ \\
\hline monitoração & ato/ação de monitorar. & monitoramento & ato/ação de monitorar. \\
\hline negociação & ato ou efeito de negociar. & negociamento & ato ou efeito de negociar. \\
\hline ofuscação & $\begin{array}{l}\text { ato/ação de impedir de } \\
\text { enxergar alguma coisa. }\end{array}$ & ofuscamento & $\begin{array}{l}\text { ato/ação de impedir de } \\
\text { enxergar alguma coisa. }\end{array}$ \\
\hline ondulação & $\begin{array}{l}\text { movimento sinuoso de } \\
\text { algo ou série de saliências } \\
\text { e depressões de uma } \\
\text { superfície. }\end{array}$ & ondulamento & $\begin{array}{l}\text { série de saliências e } \\
\text { depressões de uma } \\
\text { superfície. }\end{array}$ \\
\hline ordenação & $\begin{array}{l}\text { cerimônia religiosa } \\
\text { para colação de ordens } \\
\text { sacras ou disposição dos } \\
\text { elementos de um conjunto } \\
\text { segundo uma relação de } \\
\text { ordem. }\end{array}$ & ordenamento & ato/efeito de organizar. \\
\hline recepção & $\begin{array}{l}\text { ação ou efeito de receber } \\
\text { pessoas, ter uma reunião } \\
\text { ou local para recepcionar } \\
\text { pessoas, dar acolhimento. }\end{array}$ & recebimento & ato de cobrar e receber. \\
\hline regulação & $\begin{array}{l}\text { ato ou efeito de regular } \\
\text { (-se). }\end{array}$ & regulamento & $\begin{array}{l}\text { conjunto das medidas legais } \\
\text { ou regulamentares que } \\
\text { regem um assunto, uma } \\
\text { instituição, um instituto. }\end{array}$ \\
\hline salvação & $\begin{array}{l}\text { ação ou efeito ou resultado } \\
\text { do ato de salvar (-se), de } \\
\text { libertar (-se). }\end{array}$ & salvamento & ato ou processo de salvar. \\
\hline xingação & $\begin{array}{l}\text { ato de proferir palavrões, } \\
\text { xingos ou sequência } \\
\text { prolongada ou troca } \\
\text { agressiva de termos } \\
\text { infamantes; xingatório. }\end{array}$ & xingamento & ato de proferir xingos. \\
\hline
\end{tabular}

Fonte: Elaboração própria 
- Uma reflexão acerca do paradigma de nomes deverbais com os sufixos -ção e -mento em Português Brasileiro Contemporâneo

A seguir analisaremos, semanticamente, cada par encontrado, em determinados contextos, durante a coleta de dados:

\section{a) Abreviação e Abreviamento}

Abreviação, como pudemos observar, ocorre, nos contextos por nós analisados, como termo técnico da gramática; uma redução de uma palavra (...Nos casos de redução ou abreviação, também temos uma palavra formada...), embora também possa ter outros significados, e ocorrer em outros contextos, como aponta o dicionário Houaiss. Já abreviamento ocorre com o sentido de encurtamento de tempo (...Congresso debate abreviamento de mandatos na Bolívia...).

Observamos que poderíamos trocar a palavra abreviamento por abreviação nos contextos encontrados, no entanto, trocar abreviação por abreviamento no contexto de uso técnico se mostra complicado, pois abreviamento não carrega o sentido de termo técnico, indica o processo de se encurtar algo, enquanto abreviação, além de indicar também o processo, tem o significado técnico, ou seja, pode nomear uma palavra que foi encurtada, uma abreviatura. Estatisticamente, como aponta o dicionário Houaiss, a palavra abreviamento é menos usada que abreviação.

\section{b) Aceleração e Aceleramento}

Aceleração e aceleramento aparecem nos contextos destacados para este trabalho com o significado de "ato ou efeito de acelerar(-se)", isto é, aumento progressivo de velocidade, sem nenhuma conotação mais específica ou técnica como podemos observar nas frases "...e qualquer esforço para o aceleramento da industrialização, para tirar o..." e "... de cobre resultante de aceleração do crescimento produzida por uma...".

Assim notamos que essas palavras poderiam ser trocadas nos contextos sem que houvesse alguma mudança de significado nas frases, ou seja, poderíamos dizer "aceleração da industrialização" e "aceleramento do crescimento" sem prejuízo semântico nas sentenças. Nesses contextos, como as palavras derivadas em -ção e -mento ocorrem em combinação com outras também derivadas por esses sufixos, pode ser que os autores tenham optado por "aceleramento da industrialização" e "aceleração do crescimento", por uma questão de estilo e para evitar a repetição do sufixo no sintagma. 


\section{c) Acomodação e Acomodamento}

Acomodação ocorre com o sentido de "local ou quarto para hospedar alguém" como vemos na frase "...Esqueci-me de mandar reservar acomodação para o doutor que vem..." e também aparece com o sentido de "capacidade de acomodar pessoas" em "... claro, o palco não dá acomodação para tanta gente...". Acomodamento aparece também com o primeiro sentido que encontramos para acomodação em "...se aliviava qualquer, feliz no acomodamento, espairecia. Era capaz de brincar...", trecho extraído de Campo Geral escrito por Guimarães Rosa.

Como se trata de um texto literário, podemos pensar que talvez o autor tenha feito uso de acomodamento e não acomodação por questões de estilo, já que a literatura pode explorar a linguagem para causar um estranhamento e surpresa no leitor. Por fim, encontramos acomodamento com o sentido de "capacidade de adequação" no trecho “...alienação do mundo e o acomodamento racional a ele. Sua famosa...". Observamos que poderíamos trocar acomodação por acomodamento e acomodamento por acomodação sem maiores problemas, talvez a frase "...claro, o palco não dá acomodamento para tanta gente..." soasse um pouco estranha ao falante, mas ainda assim poderíamos entendê-la.

\section{d) Bifurcação e Bifurcamento}

Observando os contextos de ocorrência, tanto bifurcação quanto bifurcamento aparecem com significado de "divisão ou separação de alguma coisa em dois ramos ou braços (tal como uma forquilha)", seguindo o dicionário Houaiss. Na frase "...aflito e se fechava a bifurcação com um pedaço de pau...", poderíamos colocar a palavra bifurcamento sem prejuízo ao seu sentido, assim como trocar bifurcamento por bifurcação na frase "...O corte de meristema apical geralmente resulta num bifurcamento, o que ocasiona um atraso no crescimento da planta, e se o destino do plantio for madeira..." aparentemente, também não mudaria seu significado. Contudo, podemos considerar que por ser um texto de caráter científico, o termo bifurcamento pode estar sendo usado com um caráter mais especializado e isso poderia interferir no intercâmbio mais livre entre essas palavras.

\section{e) Brotação e Brotamento}

A palavra brotação aparece em duas acepções nos contextos analisados. Primeiramente com o sinônimo de broto, que é uma planta jovem, no fragmento "... Colletotrichum gloeosponoides, que ataca a brotação, as folhas, as flores e..." e depois com o sentido de um "tipo de reprodução assexuada" no trecho "...vegetativo, isto é, antes da 
- Uma reflexão acerca do paradigma de nomes deverbais com os sufixos -ção e -mento em Português Brasileiro Contemporâneo

brotação - pode proporcionar muito ganho de...". Brotamento aparece nos dois contextos observados com o mesmo sentido que brotação no segundo exemplo, como podemos ver no fragmento "...Reproduzem-se também assexuadamente, por brotamento, por regeneração...". Vemos que esses derivados sofreram uma especialização de sentido no campo da botânica. Nestes casos, trocar as palavras nas frases, aparentemente, não traria prejuízo de sentido, nem mesmo na primeira frase já que brotamento, segundo o dicionário Houaiss, também pode significar broto. Entretanto, devemos levar em consideração que em um contexto de uso mais especializado no campo da botânica e semelhantes, essa troca pode não ser viável.

\section{f) Castração e Castramento}

Castramento ocorre apenas com significado de "ato/ação de privar dos órgãos da reprodução" como podemos ver no fragmento "...Gostaria de saber se o castramento do cão macho prejudica o animal de alguma forma e se posso ter problemas no futuro...". Castração aparece com o mesmo significado na frase "...último caso as irradiações ocasionam castração simultânea...", retirada da literatura técnica médica sobre obstetrícia, e em "O complexo de castração consiste em uma diversidade de crenças e emoções infantis relacionadas com a consciência nascente de uma identidade sexual definida..." retirada de um site especializado em psicanálise e sexualidade, vemos que a palavra castração, neste contexto, pode ser interpretada como termo técnico de psicologia. Por isso, podemos inferir que o vocábulo sofreu algumas derivações de sentido podendo significar algum tipo de limitação sexual ou algum problema relacionado à sexualidade que acontece com um indivíduo. Exceto neste último trecho em que a palavra castração é usada como termo técnico, podemos trocar os dois derivados observados sem prejuízos de sentido.

\section{g) Congelação e Congelamento}

Encontramos a palavra congelação com o sentido de "ato ou efeito de congelar (-se)" como no exemplo "...Pré-diluição e congelação de sêmen suíno em água de coco in natura, após três diferentes pré-tratamentos de incubação..." já congelamento aparece com um sentido metafórico de "ato ou efeito de a autoridade competente fixar valores, preços, salários" (seguindo o Houaiss) em contexto econômico como no fragmento do jornal Diário do Nordeste: "...final do ano passado um congelamento de preços até dezembro...". Podemos trocar as palavras como em "...Pré-diluição e congelamento de sêmen suíno em água de coco in natura, após três diferentes pré-tratamentos de incubação..." e "...final do ano passado uma congelação de preços até dezembro..." sem que tenhamos dificuldade de entendimento ou mudança de significados. 


\section{h) Degradação e Degradamento}

Tanto degradação quanto degradamento apareceram nos fragmentos com o significado de "ato/ação de deteriorar", isto é, destruir ou estragar algo, como podemos observar em "...é necessária a utilização de energia obtida pela degradação do glicogênio trazida pela corrente..." e “...Gerará o degradamento do poder judiciário e o descontentamento com atividade legislativa". Aqui, poderíamos trocar uma palavra pela outra sem notar grandes diferenças semânticas nos trechos.

\section{i) Filtração e Filtramento}

Filtração e Filtramento aparecem com o significado de "ato/ação de filtrar de modo a retirar impurezas" como em "...fornecer vasilhames para armazenamento desta dotados de condições higiênicas, implantado, se necessário, sistema adequado para o filtramento da água..." e "...A hemodiálise imita a filtração glomerular e a membrana artificial...". Em um dos fragmentos encontrados, o significado do nome tem uma conotação de metáfora de "separação do essencial ou desejado", ou seja, de selecionar o que se quer como podemos ver em "... a funcionalidade de controle de volumes de correio, prevenção de ataques, filtramento de conteúdos, encriptação...". Observando os contextos vemos que poderíamos aqui também trocar as palavras sem prejuízo ao entendimento das sentenças como em "... a funcionalidade de controle de volumes de correio, prevenção de ataques, filtração de conteúdos, encriptação...".

\section{j) Isolação e Isolamento}

Isolação aparece nos fragmentos com o significado de "ato/ação isolar", como podemos ver "...Encontre as melhores empresas de Serviços de Isolação Térmica, no Busca Pé..." e "...A COBERPLAN nasceu em agosto de 1987 com o objetivo de atuar no mercado da construção civil no segmento de Impermeabilização e Isolação Térmica...". Aqui vemos a palavra isolação associada à palavra térmica formando o sintagma nominal isolação térmica que é um tipo de proteção para conservar a temperatura quente ou fria dependendo da necessidade; segundo o dicionário Houaiss, a palavra isolação é pouco usada. Isolamento aparece na acepção de "ação/ato de separar algo em determinado contexto" como "...cheguei perto das cordas de isolamento...", aqui também temos um sintagma cordas de isolamento que dá nome a uma corda com a função específica de não permitir que as pessoas se aproximem de algo. 
- Uma reflexão acerca do paradigma de nomes deverbais com os sufixos -ção e -mento em Português Brasileiro Contemporâneo

Encontramos também a palavra isolamento com significado de "estado da pessoa que vive isolada, que se pôs ou foi posta à parte", seguindo o dicionário Houaiss, em "...ele talvez estivesse padecendo maior isolamento e muito mais amarga solidão...." Poderíamos trocar uma palavra pela outra (exceto talvez na expressão cordas de isolamento, pois não encontramos na internet e nem nos dados do LabLEX o sintagma *cordas de isolação), já que a palavra isolação é pouco usada e bastante neutra, não sofreu nenhuma especialização considerável, mesmo no contexto do sintagma isolação térmica, isolação poderia ser trocada por isolamento, como vemos em vários sites.

\section{k) Monitoração e Monitoramento}

Monitoração e monitoramento aparecem aqui com o sentido de "ato/ação de monitorar", atividade que consiste em observar de maneira contínua algo do interesse do indivíduo como vemos em "...motora pressupõe a existência de monitoramento constante do ato motor..." e "...Controle e monitoração de dados como temperatura, pressão, vácuo...". Assim, poderíamos trocar essas palavras sem problemas para o entendimento da frase.

\section{I) Negociação e Negociamento}

Negociação e negociamento aparecem com a concepção de "ato ou efeito de negociar", isto é, de se fazer um acordo a respeito de algum assunto, como vemos nos contextos "...da história, e proibiam qualquer negociação, tudo o que eu devia..." e "...pergunta: interessei em fechar negócio, mas preciso saber mais a respeito do caminhão $e$ forma de negociamento...". Podemos trocar aqui negociamento por negociação e negociação por negociamento sem problemas como podemos ver em "...da história, e proibiam qualquer negociamento, tudo o que eu devia..." e "...pergunta: interessei em fechar negócio, mas preciso saber mais a respeito do caminhão e forma de negociação...".

\section{m) Ofuscação e Ofuscamento}

Tanto ofuscamento quanto ofuscação aparecem com o sentido de "ato/ação de impedir de enxergar alguma coisa", muitas vezes por conta de uma luz forte como vemos em "... o ofuscamento é o prejuízo na função visual causado pela presença de uma fonte de luz localizada no campo visual" e "...e, após alguns segundos de ofuscação, volta de novo ao cativeiro...". Nesses contextos poderíamos substituir os derivados sem problemas de entendimento das frases. 


\section{n) Ondulação e Ondulamento}

Ondulação aparece primeiramente como ato ou ação de ondular, com o sentido de "movimento sinuoso de algo", no caso encontrado trata-se do som: "...me perturbar. Era como uma ondulação de gritos que vinham e...". Nos outros casos, tanto ondulação quanto ondulamento aparecem com significado de "série de saliências e depressões de uma superfície" como podemos ver em "...escuro, justo, que acompanhava cada ondulação de suas curvas perfeitas..."; "dependendo da colocação do implante, ele pode às vezes criar um efeito colateral indesejável conhecido como ondulamento (consulte a seção Riscos)..." e "... Notou um efeito de ondulamento quando movimenta a tela do vídeo?...". Diante dessas ocorrências, podemos observar que a troca das palavras não iria afetar o significado das frases, mesmo na primeira: "...me perturbar. Era como um ondulamento de gritos que vinham e...". Segundo o dicionário Houaiss, a palavra ondulamento é menos usada do que ondulação.

\section{o) Ordenação e Ordenamento}

Primeiramente, ordenação aparece com o significado de "cerimônia religiosa para colação de ordens sacras" como vemos na frase "...com aqueles que recebiam a ordenação sacerdotal..." e também com o sentido de "disposição dos elementos de um conjunto segundo uma relação de ordem", seguindo o dicionário Houaiss, um sentido mais usado na matemática: "...Algoritmos de ordenação externa manipulam conjuntos de valores que podem estar...". Já ordenamento aparece com um sentido de "ato/efeito de organizar", isto é, um conjunto de operações destinadas a manter algo em ordem, como vemos em "...do Sul insere-se no ordenamento geral dos centros vitais..." e também com sentido de termo técnico jurídico que significa "o que tem força legal, como, por exemplo, lei, decreto, mandado, regulamento", segundo o dicionário Houaiss, como vemos no exemplo "...indígena, mas, sim a um ordenamento jurídico por meio do qual...".

Nestes contextos, poderíamos trocar ordenamento por ordenação na frase "...do Sul insere-se no ordenamento geral dos centros vitais..." que ficaria "...do Sul insere-se na ordenação geral dos centros vitais...", embora nos outros contextos ordenação tenha significados específicos, como podemos observar em seu uso religioso e matemático. Também poderíamos trocar ordenamento por ordenação no contexto jurídico, pois segundo o dicionário Houaiss, ordenação também possui este significado, assim teríamos "...indígena, mas, sim a uma ordenação jurídica por meio da qual...". 
- Uma reflexão acerca do paradigma de nomes deverbais com os sufixos -ção e -mento em Português Brasileiro Contemporâneo

\section{p) Recepção e Recebimento}

Recepção e recebimento, casos que já foram comentados na introdução deste artigo, é o único par analisado que, observado sob uma visão sincrônica, sofre alterações na base dos derivados, o que acaba diferenciando-o. São também os únicos derivados de verbo da segunda conjugação; o restante dos pares é apenas derivado da primeira conjugação. Recepção aparece aqui também como o sentido de "ação ou efeito de receber pessoas, ter uma reunião" que pode ser uma festa ou um jantar, por exemplo, como vemos no trecho "...Em lugar de uma recepção, teremos duas..." e aparece também como o sentido de "local para recepcionar pessoas, dar acolhimento" como observamos em "...Dentro da saleta de recepção, decorada com pequenos quadros do...".

Recebimento aparece como "ato de cobrar e receber"; em "...receita e despesas, desequilibrio entre pagamento e recebimento, falta de controle sobre os..."; trata-se de recebimento de dinheiro e em "... Velho são os centros de recebimento, produção e exportação clandestina de..." trata-se de recebimento de mercadorias. Como já comentamos, trocar recebimento por recepção não seria adequado nesses contextos, pois essas palavras sofreram derivações de sentido através do uso; o falante reconhece em recepção traços semânticos inexistentes em recebimento.

\section{q) Regulação e Regulamento}

Regulamento aparece aqui, nos dois contextos analisados, como um "conjunto das medidas legais ou regulamentares que regem um assunto, uma instituição, um instituto" como podemos ver no exemplo "...pessoalmente. Não fora o regulamento do hotel proibir...". Já regulação aparece com o sentido de "ato ou efeito de regular(-se)" como podemos ver em "...Existem ações puramente hormonais, como a regulação da secreção do...". Como podemos observar, os dois derivados têm aqui significados bastante diferentes, por isso trocá-los não seria adequado, já que regulamento adquiriu o sentido de "leis", ou seja, esta palavra sofreu uma especialização de sentido, um processo de deriva semântica que regulação não sofreu. Regulação poderia ser substituída apenas por outro derivado, como regulagem, mas regulamento não poderia ser substituído.

\section{r) Salvação e Salvamento}

Salvação aparece primeiramente com o sentido de "ação ou efeito ou resultado do ato de salvar(-se), de libertar(-se)" como vemos na frase "...amarela. Percebi que não havia salvação para mim..." e também aparece em contexto religioso no trecho "...salvação da 
minha alma depois da...". Nesta frase podemos observar que salvação está com o sentido de "felicidade eterna obtida após a morte", seguindo o dicionário Houaiss da Língua Portuguesa.

Já salvamento aparece como "ato ou processo de salvar", indicando um procedimento e não uma ação concluída como vemos em "...ninguém morreria e que o salvamento era só questão de tempo..." e "...com esperanças embora remotas de salvamento - ele arriscava a última...". Assim, não poderíamos substituir uma pela outra sem afetar o sentido das frases, como vemos nesta troca: "...ninguém morreria e que a salvação era só questão de tempo...", aqui a frase passou a ter um sentido religioso de salvação da alma. Também não poderíamos substituir salvação por salvamento em uma frase como "...salvação da minha alma depois da...", pois salvamento não carrega a especificação de sentido com carga de religiosidade e libertação, assim uma frase como "...salvamento da minha alma depois da..." soaria estranha aos falantes do português.

\section{s) Xingação e Xingamento}

Por fim, o último par considerado para nossa observação é xingação e xingamento. Xingação aparece como "ato de proferir palavrões, xingos" ou, segundo o dicionário Houaiss "sequência prolongada ou troca agressiva de termos infamantes; xingatório", como podemos ver em "...No servidor é uma xingação sem fim, mas ninguém tem peito pra vir cá encarar o leão..." e "... a sua capacidade de criticar os outros e também, de agüentar ser criticado... e isso tudo, sem partir para xingação. Taí, acho que ia ser legal...". Este parece ser um uso típico do -ção iterativo.

Já xingamento, além de poder significar também o "ato de proferir xingos" como vemos na frase "...E cheguei à conclusão de que o Brasil precisa recuperar a arte do xingamento, que já foi mais refinada, mais contundente e muito mais eficaz...", pode ser interpretado também como "xingo", ou seja, não como o ato ou a ação de se proferir xingos, mas também como sinônimo de xingo ou palavrão, como vemos em "...Mas duvido que alguém tenha feito um xingamento tão digressivo, com tanta verve poética, quanto um dos nossos mais assíduos comentaristas, o corintiano...".

Exceto quando xingamento está significando uma palavra, um xingo, poderíamos trocar uma palavra pela outra, como nas frases "...E cheguei à conclusão de que o Brasil precisa recuperar a arte da xingação, que já foi mais refinada, mais contundente e muito mais eficaz..." e "...No servidor é um xingamento sem fim, mas ninguém tem peito pra vir cá encarar o leão...". Apenas a frase "...Mas duvido que alguém tenha feito uma xingação tão digressiva, com tanta verve poética, quanto um dos nossos mais assíduos comentaristas, o corintiano..." 
- Uma reflexão acerca do paradigma de nomes deverbais com os sufixos -ção e -mento em Português Brasileiro Contemporâneo

tem seu sentido modificado, em vez de termos um "xingo tão digressivo" passamos a ter "uma sequência de xingos tão digressivos".

\section{Considerações finais}

Esperávamos encontrar as palavras com significados bastante distintos ou ocorrendo em diferentes contextos, justamente por conta dos processos de deriva semântica. No entanto, isso ocorre de maneira mais nítida em alguns vocábulos como, por exemplo, em salvação/salvamento, recepção/recebimento, ordenação/ordenamento, regulação/regulamento e, um pouco, em xingação/xingamento enquanto nos outros pares as diferenças semânticas e de contexto não são tão significativas. Talvez esse fenômeno possa ser explicado pelo fato de uma das formas ser mais usada que a outra, sendo assim estabelece-se uma restrição de frequência de uso, ou seja, apesar das formas existirem uma pode ser preferida pelo falante e, portanto, mais usada.

No caso de salvação, podemos observar pelos contextos em que ocorre que tem um significado de "resultado do ato de salvar", mesmo em contexto religioso quando a pessoa espera ter "salva" a sua alma, enquanto salvamento se mantém mais na acepção "ação de salvar". Podemos dizer que salvação possui um significado de ação concluída, um sentido de acabado, enquanto salvamento indica o "processo de ser salvo". No caso de recepção/recebimento, como já foi comentado, podemos depreender um traço semântico relacionado à "pessoa" na palavra recepção, traço ausente na palavra recebimento. Regulação indica "ação de regular algo" enquanto regulamento é mais usada na sua versão lexicalizada "conjunto de regras"; ordenação possui significados mais técnicos em algumas áreas, como a religiosa e jurídica, enquanto ordenamento se encontra mais neutro, mas também aparece no corpus em contexto jurídico.

Por fim, em xingamento/xingação percebemos que a primeira forma pode designar "xingo" em alguns contextos, enquanto a segunda ocorre com o significado de "sequência de xingos", numa acepção mais jocosa, que, como dissemos, vem se tornando comum em derivados em -ção, sobretudo na linguagem falada e nas novas criações lexicais. Encontramos pessoas falando em "casação" com significado brincalhão de "sequência desenfreada de casamentos", "quebração" de coisas, entre outros exemplos. Esta é, segundo Maroneze (2005), uma tendência das novas formações em -ção, muitas delas sem registros escritos ou atestadas em dicionários.

Podemos observar a partir dos dados que, quando temos uma forma com o sufixo -ção e outra com o sufixo -mento a partir de uma mesma base, pode existir uma tendência de que a forma com o sufixo -ção seja a preferida pelos falantes de Português na atual 
sincronia da língua. A princípio não encontramos uma motivação para este fato, mas temos uma hipótese, que necessita de maiores estudos para ser confirmada, de que a forma em -ção pode ser a preferida por ser mais produtiva do que formas com o sufixo -mento, já que existem muito mais formações em -ção atestadas no dicionário Houaiss da Língua Portuguesa e encontramos as formações em--ção ocorrendo em maior quantidade nos dados do LabLEX e também no Google.

Notamos também que nem todas as formas que coexistem sofrem especializações significativas no uso, mas é possível que uma delas seja mais usada que a outra. Vale ressaltar que não nos detivemos de maneira mais aprofundada sobre o uso dos sufixos em Português Europeu, uma vez que as diferenças de uso e produtividade dos nomes em -ção e -mento entre o Português Europeu e Português Brasileiro é sem dúvida algo que merece ser melhor estudado.

\section{Referências}

ARONOFF, M. World formation in generative grammar. Cambridge: MIT, 1976.

BASILIO, M. Estruturas lexicais do português: uma abordagem gerativa. Rio de Janeiro: Ática, 1980.

BASILIO, M. Formação e uso da nominalização deverbal sufixal no português falado. In: CASTILHO, A. T. de; BASILIO, M. (org.). Gramática do português falado. v. IV: Estudos descritivos. Campinas: UNICAMP, 1996. p. 23-33.

BASÍLIO, M. Formação de Palavras no Português do Brasil. São Paulo: Contexto, 2006.

BASÍlıO, M. Teoria Lexical. São Paulo: Ática, 1987. (Série Princípios).

CHAFE, W. L. Meaning and the structure of language. Chicago: The University of Chicago Press, 1970. Tradução Maria Helena Moura Neves et al. Significado e estrutura lingüística. Rio de Janeiro: Livros Técnicos e Científicos, 1979.

DI-LILO, A. Morphologie des noms en (-t)-ion du français. Cahiers de Lexicologie. Paris: Didier Larousse. v. XLIII, 1983.

Dicionário Eletrônico Houaiss da Língua Portuguesa versão 1.0.7 de setembro de 2004. 
- Uma reflexão acerca do paradigma de nomes deverbais com os sufixos -ção e -mento em Português Brasileiro Contemporâneo

Google. http://www.google.com.br. Acesso em: 27 set. 2008.

ILARI, R. Introdução à semântica: brincando com a gramática. São Paulo: Contexto, 2013.

ILARI, R.; GERALDI, J. Semântica. São Paulo: Ática, 2003.

LOPES, I. C.; PIETROFORTE, A. V. S. A semântica lexical. In: FIORIN, J. L. (org.). Introdução à linguística II: princípios de análise. São Paulo: Contexto, 2004

LYONS, J. Introdução à linguística teórica. São Paulo: Nacional, 1979.

MARONEZE, B. O. Um estudo da nominalização no Português do Brasil com base em unidades lexicais neológicas. 2005. Dissertação (Mestrado em Filologia e Língua Portuguesa) - Faculdade de Filosofia, Letras e Ciências Humanas, Universidade de São Paulo, São Paulo, 2005.

OLIVEIRA, S. M. Os sufixos nominalizadores -ção e -mento. Estudos Lingüísticos, v. XXXVI, n. 1, p. 87-96, jan./abr. 2007.

QUADROS, E. S. de. Competição morfológica e ilhas de confiabilidade na morfologia derivacional. 2015. Dissertação (Mestrado em Letras) - Instituto de Letras, Universidade Federal do Rio Grande do Sul, Porto Alegre, 2015.

RIO-TORTO, G. M. Mecanismos de Produção Lexical no Português Europeu. Revista Alfa, São Paulo: Editora UNESP, v. 42, p. 15-32, 1998.

ROCHA, L. C. de A. Estruturas morfológicas do Português. Belo Horizonte: Editora da UFMG, 2003.

SAID ALI, M. Gramática histórica da língua portuguesa. 8. ed. rev. e atual. São Paulo: Companhia Melhoramentos, 2001.

SANDMANN, A. J. Competência Lexical. Curitiba: Editora da UFPR, 1991.

SILVEIRA, L. M.; SCHWINDT, L. C. Alternância do uso de -ção e -mento em nominalizações no português do sul do Brasil. ReVEL, edição especial, n. 13, p. 43-61, 2016. Disponível em: www.revel.inf.br. Acesso em: 27 set. 2008. 
VIARO, M. Por trás da palavras: manual de etimologia do português. São Paulo: Globo, 2003.

COMO CITAR ESTE ARTIGO: PRADO, Natália Cristine; FAVARO, Gisela Sequini. Uma reflexão acerca do paradigma de nomes deverbais com os sufixos -ção e -mento em Português Brasileiro Contemporâneo. Revista do GEL, v. 18, n. 2, p. 105-127, 2021. Disponível em: https://revistadogel.gel.org.br/

Submetido em: 13/03/2021 | Aceito em: 26/04/2021. 